\title{
Effectiveness of Physiotherapy Intervention on the Quality of Life of Women with Breast Cancer who Underwent Sentinel Lymph Node Biopsy
}

\author{
Nuno Duarte $^{1 *}$, Pedro Aguiar ${ }^{2}$, Paula Lobato Faria ${ }^{2}$, Mário \\ Bernardo $^{3}$ \\ ${ }^{1}$ Instituto Português de Oncologia de Lisboa, Portugal \\ ${ }^{2}$ Public Health Research Center, Universidade Nova de Lisboa, Portugal \\ ${ }^{3}$ Faculdade de Ciências Médicas de Lisboa, Portugal \\ *Corresponding author: Nuno Duarte: n.duarte@ensp.unl.pt
}

\section{OPEN ACCESS}

Citation: Duarte N., Aguiar P., Faria P.L., Bernardo B., (2017) Effectiveness of Physiotherapy Intervention on the Quality of Life of Women with Breast Cancer who Underwent Sentinel Lymph Node Biopsy. Open Science Journal 2(4)

Received: $3^{\text {nd }}$ August 2017

Accepted: 10 ${ }^{\text {th }}$ October 2017

Published: $12^{\text {th }}$ October 2017

Copyright: (C) 2016 This is an open access article under the terms of the Creative Commons Attribution License, which permits unrestricted use, distribution, and reproduction in any medium, provided the original author and source are credited.

Funding: The author(s) received no specific funding for this work

Competing Interests: The author have declared that no competing interests exists.

\section{Abstract:}

Purpose: To evaluate if physiotherapy can contribute to the quality of service provided to Women with Breast Cancer who underwent sentinel lymph node biopsy (SLNB).Methods: This Quasi-experimental study addressed a sample of 172 women with breast cancer who underwent surgery with SLNB, 90 were included in the control group and 82 in the experimental group. We used the EORTC C30 and BR23 questionnaires to collect data about the quality of life (QoL) in the course of the first 9 months after surgery (months 1,3,6 and 9). The experimental group was submitted to specific physiotherapy techniques (individual and group treatments) in functional rehabilitation of women with breast cancer while the control group was the target of assessments only. Poisson regression was used to perform the calculation of the Relative Benefit (aRB) and Relative Risk (aRR) adjusted for several confounding factors at the baseline of the study. The significance level used in the study was $5 \%$ and the confidence interval (CI) was established at $95 \%$. All calculations were performed using the SPSS software, 20th version.Results: In the third month after surgery the experimental group showed a higher proportion of patients with substantial clinical improvement in the Global Health Status (GHS) $(\mathrm{aRB}=2.230 ; \mathrm{p}=0.014)$ and a lower risk of degradation of the GHS, $(\mathrm{aRR}=0.384 ; \mathrm{p}=0.011)$, Physical Function $(\mathrm{PF})(\mathrm{aRR}=0.484 ; \mathrm{p}=0.035)$, and Arm Symptoms (BRAS) $(\mathrm{aRR}=0.159 ; \mathrm{p}=0.007)$, when compared to the control group. Between the 1st and 6th month after surgery, physiotherapy seems to act as a protective factor on the degradation of GHS and PF. 
Between the 1st and 9th month after surgery the experimental group showed a higher proportion of patients with notable clinical improvement in the GHS $(\mathrm{aRB}=1.905 ; \mathrm{p}=0.038)$ and in the BRAS $(\mathrm{aRB}=1.761$; $\mathrm{p}=0.029)$ and a lower risk of degradation of the GHS $(\mathrm{aRR}=0.287$; $\mathrm{p}=0.010)$ and BRAS $(\mathrm{aRR}=0.265 ; \mathrm{p}=0.0421)$ scales, when compared to the control group. Conclusions: In the course of the acute survival phase, physiotherapy can help to improve the QoL of women with breast cancer who underwent surgeries with SLNB, giving a positive contribution to the quality of service provided to this group of patients.

Keywords: Breast cancer, Sentinel lymph node biopsy, Quality of life, Physiotherapy

\section{Introduction}

The modalities of breast cancer surgery which, in addition to breast surgery, recur to Sentinel Lymph Node Biopsy (SLNB) have significantly reduced morbidity of the upper limb and trunk on the surgery side when compared to surgeries in which an Axillary Lymph Node Dissection is performed [1-6]. However, in the acute survival phase [7,8], when oncological therapies are performed during the first year following diagnosis, the effect of therapies such as chemotherapy, radiotherapy, hormone therapy, and immunotherapy can overcome the lower aggressiveness of the surgery, leading to no differences in quality of life (QoL) between the two groups of patients [9-12].

There is evidence that it is possible to prevent some complications (or minimize their effect) throughout the acute phase of cancer treatment with oncological therapies through an early rehabilitation program [13-19] and it is known that physiotherapy and a program with specific exercises can contribute to the improvement in QoL in women with breast cancer throughout the acute phase of survival [20-32]. However, clinical practice suggests that patients undergoing SLNB surgery are rarely included in a functional rehabilitation program because it is assumed that in this surgery there is an absence of morbidity and consequently a minimal impact in their QoL. It is therefore important to clarify whether physiotherapy can contribute to the improvement in QoL in women with breast cancer undergoing SLNB surgery, to demonstrate whether physiotherapy can contribute to the quality of care provided to this group of patients. The purpose of this study was to evaluate whether physiotherapy can contribute to the improvement of the various dimensions of QoL in women with breast cancer undergoing SLNB surgery and other cancer therapies during the first 9 months after surgery. It also sought to verify whether physiotherapy can act as protective factor in the prevention of global QoL degradation, function, and symptoms in this group of patients. 


\section{Material and Methods}

A Quasi-Experimental study was carried out. QoL in women with breast cancer was evaluated through a questionnaire developed by the European Organization for Research and Treatment of Cancer (EORTC): QLQ-C30 (general for cancer patients) and its complementary questionnaire QLQ-BR23 (specific for breast cancer). The psychometric properties of this questionnaire have been tested in several studies and it has been concluded that this can be considered a valid instrument [32-34], being validated for the Portuguese population [35-37]. According to the EORTC guidelines, the global scales of QoL in terms of function and symptoms are transformed into values on a scale from 0 to 100. A high score represents a high response level. Thus, a high score for a functional scale represents a high and healthy level of functioning; a high score for the overall health status of QoL represents a high QoL, but a high score for a symptom scale represents a high level of symptomatology or problems [38]. Sociodemographic and clinical data were also collected and a questionnaire was constructed for this purpose.

A request for permission to use the questionnaires (EORTC QLQ - 30 and QLQ - BR23) was submitted to EORTC and the authorization was granted in September 2012. The project was submitted to an evaluation by the Research Council and the Ethics Council of the Francisco Gentil Portuguese Institute of Oncology in Lisbon (Instituto Português de Oncologia de Lisboa, Francisco Gentil - IPOLFG). The Clinical Research Unit of the IPOLFG gave a favorable opinion to the study on 13 March 2013, and assigned the study with the code UIC / 816.

The independent exposure variable of primary importance for this study was the physiotherapy technique (individual or group treatment) applied in the functional rehabilitation of women with breast cancer [39, 40]. Age, marital status, occupation, level of education, histopathology, type of surgery, and oncological therapies were the variables used to characterize the baseline study sample. The dependent variables analyzed were Global Health Status (GHS), Physical Functioning (PF), Role Functioning (RF), Emotional Functioning (EF), Social Functioning (SF), Future Perspective (BRFU), and Body Image (BRBI) for functioning scores; and Fatigue (FA), Pain (PA), Breast Symptoms, and Arm Symptoms (BRAS) for symptoms scores. From the concept "Minimal Clinically Important Difference" $[38,41-44]$ the following variables were defined: Improvement with Clinical Relevance (when there was a difference between the scores of two evaluations greater than 5 positive points in the global and functional QoL scales and 5 negative points in the symptoms scales); Conservative Clinical Improvement (when there was a difference between the scores of two evaluations greater than 10 positive points in the global and functional QoL scales and 10 negative points in the symptoms scales), and Clinical Degradation (when the difference between the scores of two evaluations was greater than 5 negative points in the global and functional QoL scales or greater than 5 positive points in the symptoms scales). The definition of these variables allowed the calculation of the Relative Benefit (RB) and Relative Risk (RR) in the dependent variables of the study. 
The following exclusion criteria were defined: non-acceptance of the patients to the intervention and study; other pathologies that could interfere with the results of the study (history of previous oncological pathology, relapses, joint pathologies, cognition alterations).

In this study, the GHS scale was chosen to calculate the sample size, since it is the one most often used in the reference literature [9-12]. As the study had four evaluation moments, we opted to choose the moment when the group of patients, according to our literature survey, would have a lower score in the parameter in question (GHS), that is, at 6 months after surgery. We decided to use a combined average and a combined standard deviation of the studies consulted, taking into account the sample size of the studies in the combined calculation. A 0.05 statistical significance level and a 0.80 power were considered. Regarding the expected effect, we used the values obtained in an exploratory study [45], in which the clinical improvement for the GHS variable was moderate, that is, improvement of the median value of this parameter was obtained between 10 and 20 following the physiotherapy. In this study we used the minimum value corresponding to a moderate clinical improvement, which is 10 [43]. In order to evaluate the effectiveness of the program, we deemed it appropriate to make a longitudinal observation of the outcomes at 3,6 and 9 months after surgery. According to the calculation of the sample size, the sample should have approximately 60 patients in each group, making a total number of 120 patients. The study sample comprised 172 women with breast cancer undergoing sentinel lymph node biopsy and other cancer therapies followed in the IPOLFG from March 2013 to November 2014. Of the 172 patients, 90 were included in the Control Group and 82 in the Experimental Group. All participants had access to an explanatory term of study to give informed consent. They were also informed about the protection of personal data. After their consent to participate in the study, inclusion in the Experimental or Control Group was at the choice of each patient. Data were collected at the same institution at four moments: 1st moment of evaluation (3 to 4 weeks post-surgery); 2nd moment of evaluation (3 months post-surgery); 3rd moment of evaluation (6 months post-surgery); 4th moment of evaluation (9 months post-surgery). 


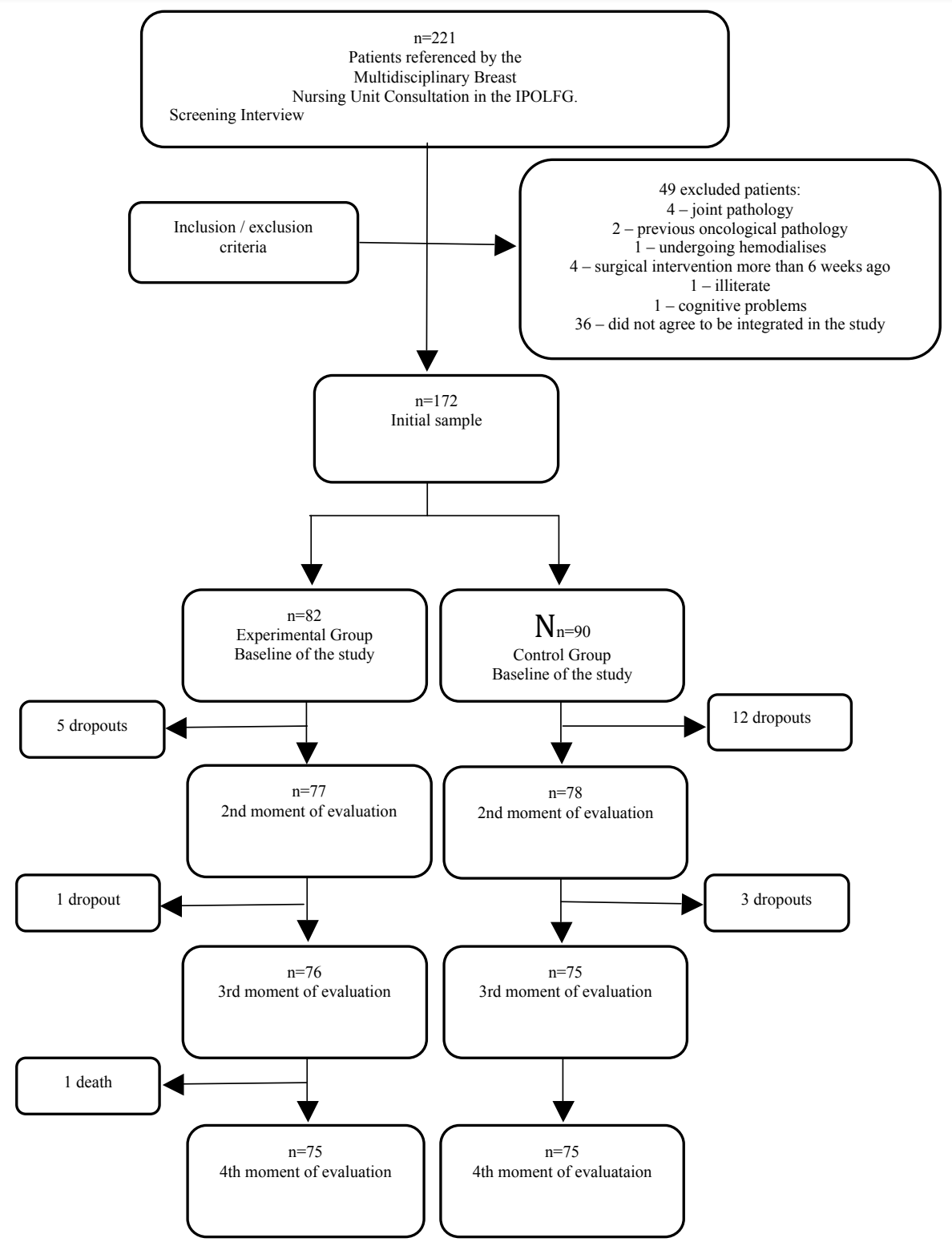

Figure 1. Evolution of the sample throughout the study

Patients who gave their consent and joined the Experimental Group underwent physiotherapy treatments (individual and group treatments) simultaneously with the oncology therapy protocol defined in the Therapeutic Decision Consultation (TDC), during the first 9 months after surgery. Individual physiotherapy treatments were performed by the same physiotherapist (25 years of experience in oncology) and group treatments (movement class) by two physiotherapists (25 and 36 years of experience in oncology). Individual physiotherapy treatments started 3 to 4 weeks after surgery, according to the protocol followed by the institution. After each moment of evaluation, whenever there was a loss of function or aggravation of the symptomatology, the patients had again the support of the physiotherapist. The type of support given by the physiotherapist always depended on the complications presented by the patient and the protocol of oncological therapies defined in the TDC. Individual physiotherapy treatments, in most cases, took place over three weeks, with an 
average of 12 treatments per patient. Techniques were used to increase articular amplitudes through maneuvers that promote pain relief and scar mobilization, and that work in breast and chest wall edemas, web syndrome, and sensitivity alterations (mobilization of the shoulder girdle, mobilization of the scar, manual lymphatic drainage, muscle stretching and neurodynamic exercises). After reaching normal joint amplitude or an amplitude near the maximum at the level of the joints of the upper limb and trunk in the affected side, the patients joined a movement class (group exercises), aiming to increase or maintain joint amplitudes of the shoulder girdle and cervical spine, increase muscle strength, and increase endurance. Patients undergoing radiotherapy treatments (RT) remained in the class until one to two weeks after the end of therapy and were informed about the need to do some of the class exercises in the following weeks. The classes took place five times per week, for a period of 20 to 30 minutes per day, and lasted for an average of 10 weeks. The exercise regimen consisted of cervical mobilization exercises, mobilization of the shoulder girdle, trunk mobilization, muscle stretching, neurodynamic exercises, postural exercises, and relaxation exercises. In the Control Group, the patients who gave their consent and were included in this study did not undergo physiotherapy treatments and only received evaluations during the first 9 months of the protocol for cancer therapies defined in the TDC. The same evaluation protocol was applied to the Experimental Group.

We used bivariable descriptive statistics for baseline sample characterization. Poisson regression was used to perform the calculation of the Relative Benefit (aRB) and Relative Risk (aRR) adjusted for several confounding factors at the baseline of the study [46]. The significance level used in the study was $5 \%$ and the confidence interval (CI) was established at 95\%. All calculations were performed using the SPSS software, 20th version.

\section{Results}

We found that the continuous variables at the baseline of the study (3 to 4 weeks after surgery) did not follow a normal distribution, so the median was used as the first comparative measure.

At the baseline of the study $(\mathrm{n}=172)$ we can assume statistical homogeneity of the two groups in terms of "Time after surgery". The groups did not present a statistical homogeneity in the variables "Age", "Number of School Years" and "Occupation" (Table 1). The Experimental Group consisted of younger women, with higher level of literacy and non-retired when compared to the Control Group. Regarding the clinical characterization, there was a statistical homogeneity in the two groups in the variables "Histopathology", "Oncology Therapies before surgery", "QT in the treatment protocol" and "RT + Hormone Therapy after surgery". 
Table 1: Comparative analysis of the Experimental versus Control Group at the baseline of the study (approximately 1 month after surgery)

\begin{tabular}{|c|c|c|c|c|c|}
\hline $\begin{array}{c}\text { Variable in } \\
\text { analysis (Baseline } \\
\text { of the study) }\end{array}$ & $\begin{array}{c}\text { Categories of the } \\
\text { variable }\end{array}$ & $\begin{array}{l}\text { Statistical } \\
\text { Measures }\end{array}$ & $\begin{array}{c}\text { Experimental } \\
\text { Group } \\
n=82\end{array}$ & $\begin{array}{c}\text { Control } \\
\text { Group } \\
n=90 \\
\end{array}$ & $p$-Value \\
\hline Age & & $\begin{array}{c}\text { Median } \\
\text { Min-Máx }\end{array}$ & $\begin{array}{l}54.50 \\
31-78 \\
\end{array}$ & $\begin{array}{c}61.15 \\
38-81\end{array}$ & $<0.001$ \\
\hline $\begin{array}{c}\text { Number of school } \\
\text { years }\end{array}$ & & $\begin{array}{c}\text { Median } \\
\text { Min-Máx }\end{array}$ & $\begin{array}{c}9.50 \\
3-20 \\
\end{array}$ & $\begin{array}{c}8.58 \\
2-20 \\
\end{array}$ & 0.017 \\
\hline $\begin{array}{c}\text { Time after surgery } \\
\text { (days) }\end{array}$ & & $\begin{array}{c}\text { Median } \\
\text { Min-Máx }\end{array}$ & $\begin{array}{c}23 \\
22-26\end{array}$ & $\begin{array}{c}23 \\
22-26\end{array}$ & 0.941 \\
\hline Marital Status & $\begin{array}{c}\text { Not married } \\
\text { Married } \\
\text { Divorced } \\
\text { Widow }\end{array}$ & $\begin{array}{l}n(\%) \\
n(\%) \\
n(\%) \\
n(\%)\end{array}$ & $\begin{array}{c}8(9.8 \%) \\
56(68.3 \%) \\
14(17.1 \%) \\
4(4.9 \%)\end{array}$ & $\begin{array}{c}8(8.9 \%) \\
65(72.2 \%) \\
8(8.9 \%) \\
9(10.0 \%)\end{array}$ & 0.276 \\
\hline Occupation & $\begin{array}{c}\text { Retired } \\
\text { Non-retired }\end{array}$ & $\begin{array}{l}n(\%) \\
n(\%)\end{array}$ & $\begin{array}{l}20(24.4 \%) \\
62(75.6 \%)\end{array}$ & $\begin{array}{l}49(54.4 \%) \\
41(45.6 \%)\end{array}$ & $<0.001$ \\
\hline Histopathology & $\begin{array}{c}\text { Carcinoma InSitu } \\
\text { Invasive Carcinoma }\end{array}$ & $n(\%)$ & $13(15.9 \%)$ & $\begin{array}{l}9(10.0 \%) \\
81(90 \%)\end{array}$ & 0.264 \\
\hline $\begin{array}{c}\text { Conservative } \\
\text { VS. } \\
\text { Mastectomy }\end{array}$ & Mastectomy & $n(\%)$ & $30(36.6 \%)$ & $\begin{array}{l}76(84.4 \%) \\
14(15.6 \%)\end{array}$ & 0.002 \\
\hline $\begin{array}{c}\text { Oncology Therapies } \\
\text { before surgery }\end{array}$ & $\begin{array}{l}\text { Yes } \\
\text { No }\end{array}$ & $\begin{array}{l}n(\%) \\
n(\%)\end{array}$ & $\begin{array}{c}0(0 \%) \\
82(100 \%)\end{array}$ & $\begin{array}{c}0(0 \%) \\
90(100 \%)\end{array}$ & \\
\hline $\begin{array}{c}\text { Chemotherapy in the } \\
\text { treatment protocol }\end{array}$ & $\begin{array}{l}\text { No } \\
Y e s\end{array}$ & $\begin{array}{l}n(\%) \\
n(\%)\end{array}$ & $\begin{array}{l}54(65.9 \%) \\
28(34.1 \%)\end{array}$ & $\begin{array}{l}61(67.8 \%) \\
29(32.2 \%)\end{array}$ & 0.789 \\
\hline $\begin{array}{c}R T+H T \text { exclusive } \\
\text { post-surgery }\end{array}$ & $\begin{array}{l}\text { No } \\
Y e s\end{array}$ & $\begin{array}{l}n(\%) \\
n(\%)\end{array}$ & $\begin{array}{l}46(56.1 \%) \\
36(43.9 \%)\end{array}$ & $\begin{array}{l}42(46.7 \%) \\
48(53.3 \%)\end{array}$ & 0.226 \\
\hline Global Health Status & & $\begin{array}{c}\text { Median } \\
\text { Min-Max }\end{array}$ & $\begin{array}{c}50.00 \\
16.67-83.33 \\
\end{array}$ & $\begin{array}{c}66.66 \\
8.33-100 \\
\end{array}$ & $<0.001$ \\
\hline Physical Functioning & & $\begin{array}{c}\text { Median } \\
\text { Min-Max }\end{array}$ & $\begin{array}{c}80.00 \\
13.33-100 \\
\end{array}$ & $\begin{array}{c}86.66 \\
26.67-100 \\
\end{array}$ & $<0.001$ \\
\hline $\begin{array}{c}\text { Role } \\
\text { Functioning }\end{array}$ & & $\begin{array}{c}\text { Median } \\
\text { Min- Max }\end{array}$ & $\begin{array}{c}66.66 \\
0.00-100\end{array}$ & $\begin{array}{c}66.66 \\
0.00-100\end{array}$ & 0.039 \\
\hline $\begin{array}{c}\text { Emotional } \\
\text { Functioning }\end{array}$ & & $\begin{array}{c}\text { Median } \\
\text { Min-Max }\end{array}$ & $\begin{array}{c}66.66 \\
0.00-100 \\
\end{array}$ & $\begin{array}{c}75,00 \\
8.33-100 \\
\end{array}$ & 0.014 \\
\hline $\begin{array}{c}\text { Social } \\
\text { Functioning }\end{array}$ & & $\begin{array}{c}\text { Median } \\
\text { Min-Max }\end{array}$ & $\begin{array}{c}66.66 \\
0.00-100\end{array}$ & $\begin{array}{c}83,33 \\
0.00-100\end{array}$ & 0.002 \\
\hline Future Perspective & & $\begin{array}{c}\text { Median } \\
\text { Min-Max }\end{array}$ & $\begin{array}{c}33.33 \\
0.00-100\end{array}$ & $\begin{array}{c}66,66 \\
0.00-100\end{array}$ & 0.003 \\
\hline Body Image & & $\begin{array}{c}\text { Median } \\
\text { Min-Max }\end{array}$ & $\begin{array}{c}83.33 \\
0.00-100 \\
\end{array}$ & $\begin{array}{c}100 \\
25.00-100 \\
\end{array}$ & 0.001 \\
\hline Fatigue & & $\begin{array}{c}\text { Median } \\
\text { Min-Max }\end{array}$ & $\begin{array}{c}33.33 \\
0.00-100\end{array}$ & $\begin{array}{c}\text { 22,22 } \\
0.00-88.89\end{array}$ & 0.004 \\
\hline
\end{tabular}




\begin{tabular}{ccccc}
\hline Pain & Median & 33.33 & 16,66 & 0.008 \\
& Min-Max & $0.00-83.33$ & $0.00-100$ & 0.059 \\
\hline \multirow{2}{*}{ Breast Symptoms } & Median & 33.33 & 25.00 & \\
& Min-Max & $0.00-100$ & $0.00-91.67$ & 11.11 \\
\hline \multirow{2}{*}{ Arm Symptoms } & Median & 33.33 & 0.001 \\
& Min-Max & $0.00-100$ & $0.00-66.67$ & \\
\hline
\end{tabular}

p-value obtained by the Mann-Whitney Test - Comparison of the numerical variables "age" and "number of school years" and the ordinal variable "literacy level". Comparison of dependent (continuous) variables, at the 1st moment of evaluation, between study groups.

p-value obtained by the Chi-square Test - Comparison of the variables "Marital status", "Occupation", "Histopathology", "Conservative VS. Mastectomy", "Chemotherapy in the treatment protocol", "RT + HT exclusive post-surgery".

QT - Chemotherapy; RT - Radiotherapy; HT - Hormone therapy; IT - Immunotherapy

All of the scales and single-item measures range in score from 0 to 100 . A high score for a functional scale represents a high / healthy level of functioning, a high score for the global health status / QoL represents a high QoL, but a high score for a symptom scale / item represents a high level of symptomatology / problems [38].

The groups did not present statistical homogeneity, in the variable "Conservative Surgery vs. Mastectomy" (Table 1). The Experimental Group presented a higher proportion of women with mastectomies. In the evaluation of the Global QoL scales, function and symptom at the baseline of the study $(\mathrm{n}=$ 172 ), there was no statistical homogeneity in the two compared groups in most of the variables under analysis. The only exception was the variable "Breast Symptoms". At the Baseline, the Experimental Group presented higher severity when compared to the Control Group. (Table 1).

\section{Most Important Results in the Analysis Performed Between the 1st and 3rd Month after Surgery $(n=155)$}

In this analysis only the measurements of Relative Benefit (RB) and Relative Risk (RR) with a substantial effect in the study are presented. As mentioned above, the groups at the baseline of the study were not homogeneous regarding some sociodemographic, clinical, and QoL variables. A model to adjust for the confounding baseline variables (Poison regression) was therefore applied. The following variables were included: age, number of school years, occupation, type of surgery, and baseline QoL variables. After adjustment for non-homogeneous factors at the baseline of the study (Table 2), the Relative Benefit value (aRB) shows that the Experimental Group (between the 1st and 3rd month postsurgery) had a higher proportion of patients with a clinical improvement in the GHS variable $(\mathrm{aRB}=2.230, \mathrm{p}=0.014)$, corresponding to a clinical improvement $123 \%$ higher than that observed in the Control Group.

Concerning the variable "Clinical Degradation", after adjustment for confounding factors at the baseline of the study, we found that in GHS variables $(\mathrm{aRR}=0.384, \mathrm{p}=0.011), \mathrm{PF}(\mathrm{aRR}=0.484, \mathrm{p}=0.035)$, and BRAS $(\mathrm{aRR}=\mathrm{P}$ $=0.007$ ), the physiotherapy may have acted as a protective factor between the 1st and 3rd month post-surgery (1st and 2nd moments of evaluation), and there was less degradation in these scales in the function and symptoms in the Experimental Group when compared to the Control Group. We can say that in the Experimental Group, between the 1st and 3rd month after surgery, there was a reduction in the risk of clinical degradation in the scales: GHS - relative risk reduction of $61.6 \%$; PF - relative risk reduction of $51.6 \%$; BRAS - relative risk 
reduction of $84.1 \%$. In the BRFU variable, the p-value reveals a trend $(\mathrm{p}<0.10)$, and the aRR values may suggest that the individuals in the Experimental Group had a lower degradation in this function scale (Table 2).

Table 2: Most important results $(\mathrm{n}=155)$ in the analysis performed between the 1st and 3rd month post-surgery (1st and 2nd moments of evaluation)

\begin{tabular}{|c|c|c|c|c|}
\hline Variable in analysis & $R B$ & $a R B$ & $R R$ & $a R R$ \\
\hline \multirow{2}{*}{$\begin{array}{c}\text { Clinical Improvement "Global Health } \\
\text { Status" }\end{array}$} & 2.76 & 2.230 & - & - \\
\hline & $P<0.001^{\text {a }}$ & $P=0.014^{b}$ & & \\
\hline \multirow{2}{*}{$\begin{array}{l}\text { Clinical Improvement "Physical } \\
\text { Functioning" }\end{array}$} & 1.75 & 1.320 & - & - \\
\hline & $P=0.001^{\mathrm{a}}$ & $P=0.314^{\mathrm{b}}$ & & \\
\hline \multirow{2}{*}{$\begin{array}{c}\text { Clinical Improvement "Arm } \\
\text { Symptoms" }\end{array}$} & 1.72 & 1.341 & - & - \\
\hline & $P<0.001^{\text {a }}$ & $P=0.212^{\mathrm{b}}$ & & \\
\hline \multirow{2}{*}{$\begin{array}{c}\text { Conservative Clinical Improvement } \\
\text { "Global Health Status" }\end{array}$} & 2.026 & 1.501 & - & - \\
\hline & $P=0.038^{\mathrm{a}}$ & $P=0.30^{\mathrm{b}}$ & & \\
\hline \multirow{2}{*}{$\begin{array}{c}\text { Conservative Clinical Improvement } \\
\text { "Physical Functioning" }\end{array}$} & 2.448 & 1.530 & - & - \\
\hline & $P=0.001^{\mathrm{a}}$ & $P=0.272^{\mathrm{b}}$ & & \\
\hline \multirow{2}{*}{$\begin{array}{c}\text { Conservative Clinical Improvement } \\
\text { "Social Functioning" }\end{array}$} & 1.59 & 1.29 & - & - \\
\hline & $P=0.037^{\mathrm{a}}$ & $P=0.395^{\mathrm{b}}$ & & \\
\hline \multirow{2}{*}{$\begin{array}{c}\text { Conservative Clinical Improvement } \\
\text { "Pain" }\end{array}$} & 1.58 & 1.330 & - & - \\
\hline & $P=0.018^{\mathrm{a}}$ & $P=0.212^{\mathrm{b}}$ & & \\
\hline \multirow{2}{*}{$\begin{array}{c}\text { Conservative Clinical Improvement } \\
\text { "Arm Symptoms" }\end{array}$} & 1.728 & 1.341 & & \\
\hline & $P<0.001^{\text {a }}$ & $P=0.212^{\mathrm{b}}$ & - & - \\
\hline \multirow{2}{*}{$\begin{array}{c}\text { Clinical Degradation "Global Health } \\
\text { Status" }\end{array}$} & - & - & 0.265 & 0.384 \\
\hline & & & $P<0.001^{\text {a }}$ & $P=0.011^{\mathrm{b}}$ \\
\hline \multirow{2}{*}{$\begin{array}{c}\text { Clinical Degradation } \\
\text { "Physical Functioning" }\end{array}$} & - & - & 0.337 & 0.484 \\
\hline & & & $P<0.001^{\text {a }}$ & $P=0.035^{b}$ \\
\hline \multirow{2}{*}{$\begin{array}{l}\text { Clinical Degradation } \\
\text { "Future Perspective" }\end{array}$} & - & - & 0.295 & 0.446 \\
\hline & & & $P<0.001^{\text {a }}$ & $P=0.085^{b}$ \\
\hline \multirow{2}{*}{$\begin{array}{l}\text { Clinical Degradation } \\
\text { "Breast Symptoms" }\end{array}$} & - & - & 0.555 & 0.713 \\
\hline & & & $P=0.017^{\mathrm{a}}$ & $P=0.290^{\mathrm{b}}$ \\
\hline \multirow{2}{*}{$\begin{array}{l}\text { Clinical Degradation } \\
\text { "Arm Symptoms" }\end{array}$} & - & - & 0.168 & 0.159 \\
\hline & & & $P<0.001^{\text {a }}$ & $P=0.007 \mathrm{~b}$ \\
\hline
\end{tabular}

$R B$ - Relative Benefit; aRB - Adjusted Relative Benefit; RR - Relative Risk; aRR - Adjusted Relative Risk

a p-value obtained by the Chi-square Test - Comparison between groups, of the percentage of individuals who obtained a Clinical Improvement, Clinical Conservative Improvement, and Clinical Degradation in the different global QoL scales, function, and symptom, between the 1st and 2nd moment of evaluation.

${ }^{\mathrm{b}}$ p-Value obtained by the Wald Test - Comparison between groups, of the percentage of individuals who obtained a Clinical Relevant Improvement, Improvement with Conservative Clinical Relevance, and Clinical Degradation in the different global QoL, function, and symptom scales, between the 1st and 2nd moments of evaluation, making an adjustment for the confounding variables at the baseline of the study.

In bold - Only the RB, aRB, RR, and aRR values that, still showed a statistically significant difference (or a trend) between groups, after being adjusted for non-homogeneous factors at the baseline of the study.

\section{Most Important Results in the Analysis Performed Between the 1st and 6th Month after Surgery $(n=151)$}

In the analysis performed between the 1st and 6th month after surgery (1st and 3rd moments of evaluation), in the calculation of the RB of the variable 
"Clinical Improvement" and "Conservative Clinical Improvement", after adjustment for non-homogeneous factors at the baseline of the study, we verified that there are no statistically significant differences between groups, allowing us to say that the RB is no longer statistically significant after adjustment for nonhomogeneous factors (Table 3 ).

Table 3: Most important results $(\mathrm{n}=151)$ in the analysis performed between the 1st and 6th month after surgery (1st and 3rd moments of evaluation).

\begin{tabular}{|c|c|c|c|c|}
\hline Variable in Analysis & $R B$ & $a R B$ & $R R$ & $a R R$ \\
\hline Clinical Improvement "Global & 1.802 & 1.474 & & \\
\hline Health Status" & $P=0.002^{\mathrm{a}}$ & $P=0.174^{\mathrm{b}}$ & & \\
\hline Clinical Improvement "Physical & 1.776 & 1.135 & & \\
\hline Functioning" & $p=0.001^{\text {a }}$ & $p=0.656^{\mathrm{b}}$ & & \\
\hline Clinical Improvement & 1.678 & 1.573 & & \\
\hline "Future Perspetive" & $p=0.020$ a & $p=0.144^{\mathrm{b}}$ & & \\
\hline Clinical Improvement & 1.714 & 1.152 & & \\
\hline "Fatigue" & $p=0.019^{\mathrm{a}}$ & $p=0.649 \mathrm{~b}$ & & \\
\hline Clinical Improvement & 1,725 & 1.429 & & \\
\hline "Pain" & $p=0.003^{\mathrm{a}}$ & $p=0.202^{\mathrm{b}}$ & & \\
\hline Clinical Improvement "Arm & 1.974 & 1.440 & & \\
\hline Symptoms" & $p<0.001^{\text {a }}$ & $p=0.163^{\mathrm{b}}$ & & \\
\hline Conservative Clinical Improvement & 1.625 & 1.051 & & \\
\hline "Global Health Status" & $p=0.056^{\mathrm{a}}$ & $p=0.885^{\mathrm{b}}$ & & \\
\hline Conservative Clinical Improvement & 2.33 & 1.074 & & \\
\hline "Physical Functioning" & $p=0.005^{\mathrm{a}}$ & $p=0.866^{\mathrm{b}}$ & & \\
\hline Conservative Clinical Improvement & 1.678 & 1.573 & & \\
\hline "Future Perspetive" & $p=0.020^{\mathrm{a}}$ & $p=0.144^{\mathrm{b}}$ & & \\
\hline Conservative Clinical Improvement & 1.802 & 1.472 & & \\
\hline "Pain" & $p=0.002^{\mathrm{a}}$ & $p=0.173^{\mathrm{b}}$ & & \\
\hline Conservative Clinical Improvement & 1.901 & 1.382 & & \\
\hline "Arm Symptoms" & $p<0.001^{\text {a }}$ & $P=0.212^{\mathrm{b}}$ & & \\
\hline Clinical Degradation"Global & & & 0.444 & 0.571 \\
\hline Health Status" & & & $p<0.001^{\text {a }}$ & $p=0.081^{\mathrm{b}}$ \\
\hline Clinical Degradation & & & 0.366 & 0.554 \\
\hline "Physical Functioning" & & & $p<0.001^{\text {a }}$ & $p=0.089 \mathrm{~b}$ \\
\hline Clinical Degradation & & & 0.370 & 0.595 \\
\hline "Future Perspetive" & & & $p=0.002^{\mathrm{a}}$ & $p=0.225^{\mathrm{b}}$ \\
\hline Clinical Degradation & & & 0.340 & 0.537 \\
\hline "Arm Symptoms" & & & $p<0.001^{\text {a }}$ & $p=0.138^{\mathrm{b}}$ \\
\hline
\end{tabular}

RB - Relative Benefit; ARB - Adjusted Relative Benefit; RR - Relative Risk; ARR - Adjusted Relative Risk

${ }^{a}$ p-value obtained by the Chi-square test - Comparison, between the groups, of the percentage of individuals who obtained Clinical Improvement, Clinical Conservative Improvement, and Clinical Degradation, in the different global QoL scales, function, and symptoms, between the 1st and 3rd moments of evaluation after adjustment for the confounding variables at the baseline of the study.

In bold - Only the RB, aRB, RR, and aRR values that, still revealed a trend in p-values $(\mathrm{p}<0.10)$ after adjustment for non-homogeneous factors at the baseline of the study.

There were no statistically significant differences of the RR for the variable "Clinical Degradation" between the 1st and 6th month post-surgery, after 
adjustment for non-homogenous factors at the baseline of the study. However, in the variable GHS $(\mathrm{aRR}=0.571 ; \mathrm{p}=0.081)$ and $\mathrm{PF}(\mathrm{aRR}=0.554, \mathrm{p}=0.089)$, the p-value showed a trend ( $\mathrm{p}<0.10)$, which may suggest that the individuals in the Experimental Group had a lower risk of deterioration in these scales (Table 3).

Most Important Results in the Analysis Performed Between the 1st and 9th Month after Surgery $(\mathrm{n}=150)$

Analyzing the variable "Clinical Improvement", between the 1st and 9th month after surgery (1st and 4th moments of evaluation), after adjustment for non-homogeneous factors at the baseline of the study, the aRB value shows that the Experimental Group submitted to physiotherapy, had a higher proportion of patients with a substantial clinical improvement in the BRAS variable $(\mathrm{aRB}=$ $1,761, \mathrm{p}=0.029), 76.1 \%$ higher than in the Control Group. In the other scales of function and symptoms there were no statistically significant differences. However, in the variable of the GHS "Clinical Improvement" (aRB $=1.639, \mathrm{p}=$ $0.054)$, the $\mathrm{p}$-value reveals a trend $(\mathrm{p}<0.10)$ and the aRB value may suggest that the benefit, in this variable, was greater in the Experimental Group. In the analysis of the variable "Conservative Clinical Improvement", between the 1st and 9th month after surgery, and with the use of the adjustment model, there were statistically significant differences in the GHS $(\mathrm{aRB}=1.905, \mathrm{p}=0.038)$ and BRAS $(\mathrm{aRB}=1.761, \mathrm{p}=0.029$ ). We can say that between the 1 st and 9 th month after surgery, the Experimental Group compared to the Control Group in the variable "Conservative Clinical Improvement" obtained a benefit of $90.5 \%$ on the GHS scale and $76.1 \%$ on the BRAS scale (Table 4).

Table 4: Most important results $(\mathrm{n}=150)$ in the analysis performed between the 1st and 9th month after surgery (1st and 4th moments of evaluation)

\begin{tabular}{|c|c|c|c|c|}
\hline Variable in Analysis & $R B$ & $a R B$ & $R R$ & $a R R$ \\
\hline $\begin{array}{l}\text { Clinical Improvement } \\
\text { "Global Health Status" }\end{array}$ & $\begin{array}{l}2.074 \\
p<0.001 \text { a }\end{array}$ & $\begin{array}{l}1.639 \\
p=0.054^{\mathrm{b}}\end{array}$ & - & - \\
\hline $\begin{array}{l}\text { Clinical Improvement } \\
\text { "Physical Functioning" }\end{array}$ & $\begin{array}{l}1.821 \\
p<0.001^{\text {a }} \\
\end{array}$ & $\begin{array}{l}1.274 \\
p=0.356^{\mathrm{b}}\end{array}$ & - & - \\
\hline $\begin{array}{l}\text { Clinical Improvement } \\
\text { "Future Perspective" }\end{array}$ & $\begin{array}{l}1.545 \\
p=0.042^{\text {a }}\end{array}$ & $\begin{array}{l}1.438 \\
p=0.231^{\mathrm{b}}\end{array}$ & - & - \\
\hline $\begin{array}{c}\text { Clinical Improvement } \\
\text { "Fatigue" }\end{array}$ & $\begin{array}{l}2.54 \\
p<0.001^{\mathrm{a}}\end{array}$ & $\begin{array}{l}1.633 \\
p=0.104^{\mathrm{b}}\end{array}$ & - & - \\
\hline $\begin{array}{l}\text { Clinical Improvement } \\
\text { "Breast Symptoms" }\end{array}$ & $\begin{array}{l}1.429 \\
p=0.001^{\text {a }}\end{array}$ & $\begin{array}{l}1.322 \\
p=0.203 \mathrm{~b}\end{array}$ & - & - \\
\hline $\begin{array}{l}\text { Clinical Improvement } \\
\text { "Arm Symptoms" }\end{array}$ & $\begin{array}{l}2.36 \\
p<0.001^{\text {a }}\end{array}$ & $\begin{array}{l}1.761 \\
p=0.029 \text { b }\end{array}$ & - & - \\
\hline $\begin{array}{c}\text { Conservative Clinical } \\
\text { Improvement "Global } \\
\text { Health Status" }\end{array}$ & $\begin{array}{l}2.412 \\
p<0.001\end{array}$ & $\begin{array}{l}1.905 \\
p=0.038\end{array}$ & - & - \\
\hline $\begin{array}{c}\text { Conservative Clinical } \\
\text { Improvement "Physical } \\
\text { Functioning" }\end{array}$ & $\begin{array}{l}2.278 \\
p<0.001^{\text {a }}\end{array}$ & $\begin{array}{l}1.356 \\
p=0.341 \mathrm{~b}\end{array}$ & - & - \\
\hline $\begin{array}{c}\text { Conservative Clinical } \\
\text { Improvement "Future } \\
\text { Perspective" }\end{array}$ & $\begin{array}{l}1.545 \\
p=0.042^{\mathrm{a}}\end{array}$ & $\begin{array}{l}1.438 \\
p=0.231^{\mathrm{b}}\end{array}$ & - & - \\
\hline
\end{tabular}




\begin{tabular}{|c|c|c|c|c|}
\hline $\begin{array}{l}\text { Conservative Clinical } \\
\text { Improvement "Fatigue" }\end{array}$ & $\begin{array}{l}2 \\
p<0.001^{\text {a }} \\
\end{array}$ & $\begin{array}{l}1.580 \\
p=0.124^{\mathrm{b}}\end{array}$ & - & - \\
\hline $\begin{array}{c}\text { Conservative Clinical } \\
\text { Improvement "Breast } \\
\text { Symptoms" }\end{array}$ & $\begin{array}{l}1.5 \\
p=0.014^{\mathrm{a}}\end{array}$ & $\begin{array}{l}1.5 \\
p=0.110^{\mathrm{b}}\end{array}$ & - & - \\
\hline $\begin{array}{c}\text { Conservative Clinical } \\
\text { Improvement "Arm } \\
\text { Symptoms" }\end{array}$ & $\begin{array}{l}2.36 \\
p<0.001 \text { a }\end{array}$ & $\begin{array}{l}1.761 \\
p=0.029\end{array}$ & - & - \\
\hline $\begin{array}{l}\text { Clinical Degradation } \\
\text { "Global Health Status" }\end{array}$ & - & - & $\begin{array}{l}0.171 \\
p<0.001^{\mathrm{a}}\end{array}$ & $\begin{array}{l}0.287 \\
p=0.010^{\mathrm{b}}\end{array}$ \\
\hline $\begin{array}{l}\text { Clinical Degradation } \\
\text { "Physical Functioning" }\end{array}$ & - & - & $\begin{array}{l}0.361 \\
p<0.001^{\text {a }}\end{array}$ & $\begin{array}{l}0.606 \\
p=0.150^{\mathrm{b}}\end{array}$ \\
\hline $\begin{array}{l}\text { Clinical Degradation } \\
\text { "Emotional Functioning" }\end{array}$ & - & - & $\begin{array}{l}0.558 \\
p=0.010^{\text {a }}\end{array}$ & $\begin{array}{l}0.650 \\
p=0.188^{\mathrm{b}}\end{array}$ \\
\hline $\begin{array}{l}\text { Clinical Degradation } \\
\text { "Future Perspective" }\end{array}$ & - & - & $\begin{array}{l}0.360 \\
p=0.001^{\text {a }}\end{array}$ & $\begin{array}{l}0.562 \\
p=0.188^{\mathrm{b}}\end{array}$ \\
\hline $\begin{array}{c}\text { Clinical Degradation } \\
\text { "Pain" }\end{array}$ & - & - & $\begin{array}{l}0.535 \\
p=0.018^{\text {a }}\end{array}$ & $\begin{array}{l}0.799 \\
p=0.529 \mathrm{~b}\end{array}$ \\
\hline $\begin{array}{l}\text { Clinical Degradation } \\
\text { "Breast Symptoms" }\end{array}$ & - & - & $\begin{array}{l}0.388 \\
p=0.015^{\text {a }}\end{array}$ & $\begin{array}{l}0.469 \\
p=0.186^{\text {b }}\end{array}$ \\
\hline $\begin{array}{l}\text { Clinical Degradation } \\
\text { "Arm Symptoms" }\end{array}$ & - & - & $\begin{array}{l}0.230 \\
p<0.001^{\text {a }}\end{array}$ & $\begin{array}{l}0.361 \\
p=0.042^{b}\end{array}$ \\
\hline
\end{tabular}

RB - Relative Benefit; aRB - Adjusted Relative Benefit; RR - Relative Risk; aRR - Adjusted Relative Risk

a p-value obtained by the Chi-square test - Comparison, between groups, of the percentage of individuals who obtained a Clinical Improvement, Improvement with Conservative Clinical Relevance, and Clinical Degradation, in the different scales of function and symptoms, between the 1st and 4 th moments of evaluation.

b p-value obtained by the Wald Test - Comparison, between groups, of the percentage of individuals who obtained a Clinical Improvement, Improvement with Conservative Clinical Relevance and Clinical Degradation, in the different scales of function and symptoms, between the 1st and 4th moments of evaluation with an adjustment for the confounding variables at the baseline of the study.

In bold - Only the RB, aRB, RR and aRR values that still showed a statistically significant difference between groups after adjustment for nonhomogeneous factors at the baseline of the study.

Table 4 shows that there were statistically significant differences in the GHS $(\mathrm{aRR}=0.287 ; \mathrm{p}=0.010)$ and BRAS $(\mathrm{aRR}=0.361, \mathrm{p}=0.042)$ of the variable "Clinical Degradation" between the 1st and 9th month after surgery after adjustment for non-homogeneous factors at the baseline of the study. In these variables the physiotherapy may have acted as a protective factor between the 1st and 9th month after surgery, as the Experimental Group registered a reduced risk of clinical GHS degradation (relative risk reduction of $71.3 \%$ ) and of BRAS (relative risk reduction of $63.9 \%$ ).

In all of the analyses performed the estimate direction with an effect favorable to the Experimental Group was maintained, even in those variables that showed no statistically significant effect, after adjustment for confounding factors at the baseline of the study.

Table 5 shows a Synthesis of the most important results of the study. 
Table 5: Synthesis of the most important results of the study (statistically significant or in trend, after adjustment for confounding factors at baseline of the study)

\begin{tabular}{|c|c|c|c|}
\hline Variable in Analysis & $\begin{array}{c}\text { Evolution from the } \\
\text { 1st to the } 2 \text { nd } \\
\text { moments of } \\
\text { evaluation }(n=155)\end{array}$ & $\begin{array}{c}\text { Evolution from the } \\
\text { 1st to the } 3 r d \\
\text { moments of } \\
\text { evaluation }(n=151)\end{array}$ & $\begin{array}{c}\text { Evolution from the } \\
\text { 1st to the } 4 \text { th } \\
\text { moments of } \\
\text { evaluation }(n=150)\end{array}$ \\
\hline $\begin{array}{c}\text { Clinical Improvement "Global Health } \\
\text { Status" }\end{array}$ & $\begin{array}{c}a R B=2.230 \\
p=0.014\end{array}$ & - & $\begin{array}{c}a R B=1.639 \\
p=0.054\end{array}$ \\
\hline $\begin{array}{l}\text { Clinical Improvement "Arm } \\
\text { Symptoms" }\end{array}$ & - & - & $\begin{array}{c}a R B=1.761 \\
p=0.029\end{array}$ \\
\hline $\begin{array}{c}\text { Conservative Clinical Improvement } \\
\text { "Global Health Status" }\end{array}$ & - & - & $\begin{array}{c}a R B=1.905 \\
p=0.038\end{array}$ \\
\hline $\begin{array}{c}\text { Conservative Clinical Improvement } \\
\text { "Arm Symptoms" }\end{array}$ & - & - & $\begin{array}{c}a R B=1.761 \\
p=0.029\end{array}$ \\
\hline $\begin{array}{c}\text { Clinical Degradation } \\
\text { "Global Health Status" }\end{array}$ & $\begin{array}{c}a R R=0.384 \\
p=0.011\end{array}$ & $\begin{array}{c}a R R=0.571 \\
p=0.081\end{array}$ & $\begin{array}{c}a R R=0.287 \\
p=0.010\end{array}$ \\
\hline $\begin{array}{l}\text { Clinical Degradation } \\
\text { "Physical Functioning" }\end{array}$ & $\begin{array}{c}a R R=0.484 \\
p=0.035\end{array}$ & $\begin{array}{c}a R R=0.554 \\
p=0.089\end{array}$ & - \\
\hline $\begin{array}{l}\text { Clinical Degradation } \\
\text { "Future Perspective" }\end{array}$ & $\begin{array}{c}a R R=0.446 \\
p=0.085\end{array}$ & - & - \\
\hline $\begin{array}{l}\text { Clinical Degradation } \\
\text { "Arm Symptoms" }\end{array}$ & $\begin{array}{l}a R R=0.159 \\
\quad p=0.007\end{array}$ & - & $\begin{array}{c}a R R=0.361 \\
p=0.042\end{array}$ \\
\hline
\end{tabular}

P-value obtained by the Wald Test - Comparison, between groups, of the percentage of individuals who obtained a Clinical Improvement, Improvement with Conservative Clinical Relevance, and Clinical Degradation in the different global QoL scales, in function, and symptoms, between the 1st and 2nd moments of evaluation, between the 1st and 3rd moments of evaluation, and between the 1st and 4th moments of evaluation, after adjustment for the confounding variables at the baseline of the study

\section{Discussion}

The results of this Quasi - Experimental study show that a physiotherapy program can greatly improve QoL in women with breast cancer undergoing SLNB surgery during the first 9 months after surgery.

In our literature review we found no other studies with a target population similar to ours. In many studies the protocol used in the experimental group did not match ours, regarding the frequency and type of intervention performed. We compared the results of our study with those performed regarding women undergoing breast cancer surgery with Axillary Lymph Node Dissection or SLNB and other oncological therapies, in which the experimental protocol included individual physiotherapy or specific treatment programs for women undergoing breast cancer surgery.

The present study found that between the 1st and 3rd month after surgery the Experimental Group had a higher ratio of patients with a statistically significant improvement in the Global Health Status $(\mathrm{aRB}=2,230)$. In the other variables, with no statistically significant effect after adjustment, the Experimental Group maintained the favorable estimate effect. This matches other studies that report a statistically significant GHS improvement in the same postsurgery period in the group submitted to physiotherapy or to an exercise program when compared to a Control Group [19, 29, 31, 47]. In the other function and 
symptoms scales there were no statistically significant differences between groups. This matches the results of other studies in which, during the same period, there were no statistically significant differences between groups in the scales for Arm Symptoms [48], Breast Symptoms [48, 49], Physical Functioning, Role Functioning, and Social Functioning [28, 48]. However, in some studies over the same period, there was a statistically significant improvement in the Experimental versus Control Group in Physical Functioning [19, 22, 31], Role Functioning [19, 22, 25], Emotional Functioning [19, 22], Social Functioning [19, 22], Pain [19, 25, 29], Breast Symptoms [19], Arm Symptoms [19, 31], and Fatigue [25].

In our study, between the 1st and 3rd month after surgery, after adjustment for non-homogenous factors at the baseline of the study, the Experimental Group showed less degradation in the Global Health Status (relative risk reduction of $61.6 \%$ ), in Physical Functioning (relative risk reduction of 51.6\%), and Arm Symptoms (relative risk reduction of $84.1 \%$ ) when compared to the Control Group, suggesting that physiotherapy acted as a protective factor. We found only one reference to the effect of an exercise scheme in the degradation of the different dimensions of QoL during the first 3 months after surgery [47]. However, although the Experimental Group registered a lower degradation in the scales of Physical Functioning, Role Functioning, and Breast Symptomes, those authors [47] report no statistically significant differences between groups.

In this study, between the 1st and 6th month after surgery, after adjustment for non-homogeneous factors at baseline of the study, we verified that there are no statistically significant differences between groups in "Clinical Improvement" and "Clinical Conservative Improvement". However, the estimate direction with an effect favorable to the Experimental Group was maintained. These results are similar to those obtained in other studies in which 6 months after surgery women with breast cancer undergoing physiotherapy or a specific exercise program presented better scores, or a higher ratio with clinical improvement when compared to a Control Group (without the intervention of physiotherapy or an exercise program), but there were no statistically significant differences between groups in the Global Health Status [21, 23, 29], Physical Functioning [23, 50], Future Perspective [23], Fatigue [21, 23] or Arm Symptoms [23]. However, in other studies, 6 months after surgery women with breast cancer who had the support of physiotherapy or a specific exercise program, compared to a Control Group, showed statistically significant or clinically important improvement in Global Health Status [20, 22], Role Functioning [20, 22], Emotional Functioning, Social Functioning [22, 26], Fatigue [20], Pain [21], Future Perspective, Breast Symptoms, and Arm Symptoms [26].

In the present study, between the 1 st and 6th month after surgery, the pvalues of Global Health Status $(\mathrm{aRR}=0.571)$ and Physical Functioning $(\mathrm{aRR}=$ 0.554) demonstrated a trend level, suggesting that the Experimental Group had a lower ratio of patients with clinical deterioration in these variables. This matches other studies in which 6 months after the surgery, women with breast cancer who did not undergo physiotherapy, when compared to a group who did, registered a greater degradation in the Global Health Status [26, 27, 51], Physical Functioning, Role Functioning, Emotional and Social Functioning [50, 51], Body Image, Future Perspective [26], and Fatigue [51]. 
Between the 1st and 9th month after surgery the Experimental Group had a higher ratio of patients with a clinical improvement in Arm Symptoms (aRB = 1.761), as well as in the conservative clinical improvement of Global Health Status $(\mathrm{aRB}=1.905)$ and Arm Symptoms $(\mathrm{aRB}=1.761)$. These results are similar to those in other studies in which there was a statistically significant improvement at the 9 th month after surgery in women with breast cancer who had the support of physiotherapy or an exercise program, when compared to women without the same type of support, in the scales of Global Health Status [24, 27, 52, 53, 54] and Arm Symptoms [54]. It should be noted that the studies by Travier et al. [51] and Gordon et al. [31] showed no statistically significant differences in the Global Health Status. In our study we registered a greater clinical improvement in the Experimental VS. Control Group in the scales of Physical Functioning, Future Perspective, Fatigue and Breast Symptoms, but without statistically significant differences. This matches some studies in which, in the 9th month after surgery, women with breast cancer undergoing physiotherapy or a specific exercise program presented better scores, but there were no statistically significant differences between groups, in the scales of Physical Functioning [21, 31], Fatigue [21, 51], and Breast Symptoms [31]. However, in other studies, in the same evaluation period, women with breast cancer who had the support of physiotherapy or an exercise program, when compared to women without that support, had statistically significant improvements in the scales of Physical Functioning [23, 24, 27, 28, 52, 54], Social Functioning [21, 23, 28, 52], Role Functioning [27, 28, 52, 53], Emotional Functioning [28, 52, 53], Pain [21, 52, 53], and Breast Symptoms [27, 28, 30].

In the present study, 9 months after surgery the Experimental Group had a lower ratio of patients with a clinical degradation of Global Health Status (aRR $=0.287)$ and Arm Symptoms $(\mathrm{aRR}=0.361)$. We did not find any studies that mentioned the effect of physiotherapy or exercise programs in the degradation of the global QoL scales, function, and symptoms after 9 months post-surgery.

The fact that there was no random selection / distribution of the patients over the study groups may have led to a lack of homogeneity of the groups at the baseline of the study in relation to some sociodemographic, clinical, and baseline scores variables. This can be a limitation, but we think it is important to mention that in the treatment of data, statistical techniques were used to correct for confounding factors at the baseline of the study. The multiple regression methods allowed us to control for confounding factors caused by the lack of basal homogeneity due to the selection bias [46].

\section{Conclusion}

This study allowed us to reach the following conclusions with a statistically significant result or at a trend level of significance:

- Physiotherapy contributes to the improvement of "Global Health Status" in women with Breast Cancer submitted to SLNB surgeries, between the 1st and 3rd month post-surgery (clinical improvement $123 \%$ higher than that determined in the Control Group); 
- Physiotherapy acts as a protective factor, reducing the risk of degradation in "Global Health Status" (61.6\% reduction of degradation risk), "Physical Functioning" (51.6\% reduction of degradation risk), and "Arm Symptoms" (84.1\% reduction of degradation risk) between the 1st and 3rd month post-surgery for breast cancer with SLNB. In this period women who have access to physiotherapy present a better "Future Perspective";

- Physiotherapy acts as a protective factor against the degradation of "Global Health Status" and "Physical Functioning" in women submitted to breast cancer surgery with SLNB between the 1st and 6th month post-surgery (although without a statistical significance);

- Physiotherapy contributes to the improvement of "Global Health Status" (clinical improvement 90.5\% higher than in the Control Group) and "Arm Symptoms" (clinical improvement 76.1\% higher than in the Control Group) between the 1 st and the 9 th month post-surgery in women with breast cancer undergoing SNLB surgery;

- Physiotherapy acts as a protective factor between the 1st and 9th month post-surgery on breast cancer with SLNB, reducing the risk of degradation of "Global Health Status" and "Arm Symptoms" (63.9\% reduction of degradation risk).

We can conclude that physiotherapy contributes to the quality of care provided to women with breast cancer undergoing SLNB surgeries during the acute phase of survival.

When we finalized this study, only women undergoing Axillary Lymph Node Dissection in breast cancer surgery could benefit from physiotherapy sessions in the IPOLFG. The evidence produced by this research made it possible to propose an alteration to this protocol, suggesting that all women with breast cancer should be submitted to an early physiotherapy program and a functional followup model throughout all stages of survival.

\section{Acknowledgements}

The authors are grateful to European Organization for Research and Treatment of Cancer for the permission to use the EORTC QLQ - 30 questionnaire and the complementary questionnaire (specific for breast cancer) EORTC QLQ - 23. They also thank those who, directly or indirectly, made this study viable. Special thanks to the Multidisciplinary Breast Nursing Unit Consultation in the Instituto Português de Oncologia de Lisboa de Francisco Gentil (IPOLFG) and to the physiotherapists Arciolinda Barros and Mariana Duarte (IPOLFG physiotherapists). 


\section{References:}

1. Kootstra JJ, Diskstra PV, Rietman H, Vries J, Baas P, Geertzen J, et al. A longitudinal study of shoulder and arm morbidity in breast cancer survivors 7 years after sentinel lymph node biopsy or axillary lymph node dissection. Breast Cancer. 2013; 139: 125-134.

2. Disipio T, Newman B, Hayes, S. Incidence of unilateral arm lymphoedema after breast cancer: a systematic review and meta-analysis. Lancet Oncology. 2013; 14: 500-515.

3. Bafford A, Godd M, Gu X, Lipsitz S, Golshan M. Diminishing morbidity with the increased use of sentinel node biopsy in breast carcinoma. American Journal of Surgery. 2010; 200:374-377.

4. Nakib M, Buttarelli M, Hulart L, Martino M, Tarpin C, Extra J, et al. Quality of life at 2 years follow-up after sentinel lymph node biopsy, immediate or delayed axillary dissection for breast cancer. The Breast Journal. 2010; 16: 555-557.

5. Mansel RE, Fallowfield L, Kissin M, Goyal A, Newcombe RG, Dixon JM, et al. Randomized multicenter trial of sentinel node biopsy versus standard axillary treatment in operable breast cancer: the ALMANAC trial. Journal of the National Cancer Institute. 2006; 98: 599-609.

6. Fleissig A, Fallowfield L, Langridge C, Johnson L, Newcombe R, Dixon J, et al. Post-operative arm morbidity and quality of life. Results of the ALMANAC randomised trial comparing sentinel node biopsy with standard axillary treatment in the management of patients with early breast cancer. Breast Cancer Research and Treatment. 2006; 95: 279-293.

7. Bloom, J. Surviving and thriving? Psycho-oncology. 2002; 11: 89-92.

8. Mullan, F. Seasons of survival: reflections of a physician with cancer. New England Journal of Medicine. 1985;313: 270 - 273.

9. Gournay E, Guymard A, Coutant C, Boulet S, Arveux P, Couseret S, et al. Impact of sentinel node biopsy on long-term quality of life in breast cancer patients. British Journal of Cancer. 2013; 109: $2783-2791$.

10. Dabakuyo T, Fraisse J, Gouseret S, Gauy S, Padeano M, Loustalat C, et al. A multicentre cohort study to compare quality of life in breast cancer patients according to sentinel lymph node biopsy or axillary lymph node dissection. Annals of Oncology. 2009; 20: $1352-1361$.

11. Kootstra J, Weebers J, Rietman H, Vries J, Baas P, Geertzen J, et al. Quality of life after sentinel lymph node biopsy or axillary lymph node dissection in stage I/II breast cancer patients: a prospective longitudinal study. Annals of surgical oncology. 2008; 15: 2533-2541.

12. Peintinger F, Reitsamer R, Ralph G. Comparison of quality of life and arm complaints after axillary lymph node dissection VS sentinel lymph node biopsy in breast cancer patients. British Journal of Cancer. 2003; 89: 648-652.

13. Levangie PK., Santasier AM, Stout NL, Pfalzer L. A qualitative assessment of upper quarter dysfunction reported by physical therapists treated for breast cancer or treating breast cancer sequelae. Support Care Cancer. 2011; 19: 1367-1378.

14. Gerber LH, Stout N, McGarvey C, Soballe P, Shieh C, Diao G, et al. Factors predicting clinically significant fatigue in women following treatment for primary breast cancer. Supportive Care in Cancer. 2011; 19: $1581-1591$.

15. Yang E, Park W, Seo K, Kim S, Heo CY, Lim JY. Longitudinal change of treatment related upper limb dysfunction and its impact on late dysfunction in breast cancer survivors: a prospective cohort study. Journal of Surgical Oncology. 2010; 101: 84-91.

16. Chan D, Lui L, So W. Effectiveness of exercise programs on shoulder mobility and lymphoedema after axillary lymph node dissection for breast cancer: systematic review. Journal of Advanced Nursing. 2010; 66: $1902-1914$.

17. Schmitz K, Ahmed R, Troxel A, Cheville A, Lewis L, Smith R, et al. Weight lifting for women at risk for breast cancer - related lymphedema: a randomized trial. Journal of the American Medical Association. 2010; 304: 2699 - 2705.

18. Johansson K, Branje E. Arm lymphedema in a cohort of breast cancer survivors 10 years after diagnosis. Acta Oncologica. 2010;49: 166-173.

19. Cho Y, Do J, Kwon O, Jeon JY. Effects of a physical therapy program combined with manual lymphatic drainage on shoulder function, quality of life, lymphedema incidence, and pain in breast cancer patients with axillary web syndrome following axillary dissection. Support Care Cancer. 2016; 24: 2047-2057.

20. Echávez J, Jiménez E, Vélez R. Effects of supervised exercise on cancer-related fatigue in breast cancer survivors: a systematic review and meta-analysis. BMC Cancer. 2015. DOI: 10.1186/s12885-015-1069-4.

21. Waart H, Struiver M, Harten W, Geleijn E, Kieffer J, Buffart L, et al. Effect of low-intensity physical activity and moderate-to high-intensity physical exercise during adjuvant chemotherapy 
on physical fitness, fatigue, and chemotherapy completion rates: results of the PACES randomized clinical trial. Journal of Clinical Oncology. 2015; 33: 1918-1927.

22. Harder H, Langridge C, Trapala I, Zammit C, Grant M, Rees D, et al. Post-operative exercises after breast cancer surgery: results of a RCT evaluating standard care versus standard care plus additional yoga exercise. European Journal of Integrative Medicine. 2015;7: 202-210.

23. Sanchez M, Lacomba M, Sánchez B, Merino A, Costa SP, Téllez EC, et al. Health related quality of life improvement in breast cancer patients: secondary outcome from a simple blinded, randomized clinical trial. The Breast. 2015; 24: 75-81.

24. Vargas A, Buchan J, Morales M. A multimodal physiotherapy programme plus deep water running for improving cancer-related fatigue and quality of life in breast cancer survivors. European Journal of Cancer Care. 2014; 23: 15-21.

25. Steindorf K, Schmitz M, Klassen O, Ulrich C, Oelmann J, Habermann N, et al. Randomized, controlled trial of resistance training in breast cancer patients receiving adjuvant radiotherapy: results on cancer-related fatigue and quality of life. Annals of Oncology. 2014; 25: 2237-2243.

26. Testa A, Iannace C, Libero L. Strengths of early physical rehabilitation programs in surgical breast cancer patients: results of a randomized controlled study. European Journal of Physical and Rehabilitation. 2014; 50: 275-284.

27. Hayes S, Rye S, DiSipio T, Yates P, Bashford J, Pyke C, et al. Exercise for health : a randomized controlled trial evaluating the impact of a pragmatic, translational exercise intervention on the quality of life, function and treatment-related side effects following breast cancer. Breast Cancer Research treatment. $2013 ; 137: 175-186$.

28. Oliveira M, Souza G, Miranda M, Okubo M, Amaral M. Silva M, et al. Exercícios para membros superiores durante radioterapia para câncer de mama e qualidade de vida. Revista Brasileira de Ginecologia e Obstetrícia. $2010 ; 32: 133-138$.

29. Beurskens C, Uden C, Strobbe L, Oostendorp R, Wobbes T. The efficacy of physiotherapy upon shoulder function following axillary dissection in breast cancer, a randomized controlled study. BMC Cancer. 2007. doi: 10.1186/1471-2407-7-166.

30. Mutrie N, Campbell AM, Whyte F, McConnachie A, Emslie C, Lee L, et al. Benefits of supervised group exercise programme for women being treated for early stage breast cancer: pragmatic randomized controlled trial. BMJournal. 2007. doi: 10.1136/bmj.39094.648553.AE.

31. Gordon L, Battistutta D, Scuffham P, Tweeddale M, Newman B. The impact of rehabilitation support services on health-related quality of life for women with breast cancer. Breast Cancer Research and Treatment. 2005;93: 217-226.

32. Scott N, Fayers P, Aaronson N, Bottomley A, Graeff A, Groenvold M, et al. EORTC QLQ C30 reference values. In: EORTC Quality of Life Group. 2008. Accessed 23 Jan 2016.

33. Sprangers M, Groenvold M, Arraras J, Franklin J, Velde A, Muller M, et al. The European organization for research and treatment of cancer breast cancer - specific quality - of - life questionnaire module: first results from a three- country field study. Journal of Clinical Oncology. 1996; 14: $2756-2768$.

34. Aaronson N, Ahmedzai S, Bergman, B, Bullinger M, Cull A, Duez NJ, et al. - The European Organization for Research and Treatment of Cancer QLQ-C30: A Quality-of-Life Instrumemt for Use in International Clinical Trials in Oncology. Journal of the National Cancer Institute. 1993; 85: $365-376$.

35. European Organisation for Research and Treatment of Cancer. List of translations available by language - validate modules and C30. In: Modules. 2016. http://groups.eortc.be/qol/eortc-qlqc30. Accessed 10 Jun 2016.

36. Ribeiro J, Pinto C, Santos C. Validation study of the Portuguese version of QLQ - C30 - V3. Psicologia, Saúde \& Doenças. 2008; 9: 89-102.

a. 37 Ferreira, P. The Portuguese version of the EORTC QLQ-C30. Gynaecological Oncology. 1997; 527-532.

37. Fayers P, Aaronson N, Bjordal K, Groenvold M, Curran O, Battomley A, et al. The EORTC QLQ-C30 scoring manual. 3rd ed. Brussels: European Organisation for Research and Treatment of Cancer, 2001.

38. Harris S, Schmitz K, Campbell KL, McNeely M. Clinical practice guidelines for breast cancer rehabilitation. Cancer. $2012 ; 2312-2324$.

39. Leduc, O. European consensus: rehabilitation after breast cancer treatment. The European Journal of Lymphology. 2008; 19: 13 - 20.

40. Cocks K, King M, Velikova G, Castro G, St-James M, Fayers PM, et al. Evidence-based guidelines for interpreting change scores for the European organisation for research and treatment of cancer quality of life questionnaire core 30. European Journal of Cancer. 2012; 48: 1713-1721. 
41. Osoba D. Interpreting the meaningfulness of changes in health-related quality of life scores: lessons from studies in adults. Int. Journal Cancer: Supplement. 1999; 12: 132-137.

42. Osoba D, Rodrigues G, Myles J, Zee B, Pater J. Interpreting the significance of changes in health-related quality - of- life scores. Journal of Clinical Oncology.1998; 16: 139-144.

43. Lydic E, Epstein R. Interpretation of quality of life changes. Quality of Life Research. 1993;2: 221-226.

44. Duarte N. Fisioterapia: influência na qualidade de vida da mulher com cancro da mama contributo para a qualidade do serviço em oncologia. Lisboa: Escola Nacional de Saúde Pública. Universidade Nova de Lisboa, 2010. Dissertação elaborada no âmbito do Curso de Mestrado de Gestão em Saúde ministrado pela ENSP- UNL.

45. Aguiar P, Nunes B. Odds ratio: reflexão sobre a validade de uma medida de referência em epidemiologia. Acta Médica Portuguesa. 2013; 26: 505-510.

46. Campbell A, Mutrie N, White F, McGuire F, Kearney N. A pilot study of a supervised group exercise programme as a rehabilitation treatment for women with breast cancer receiving adjuvant tratment. European Journal of Oncology Nursing. 2005; 9: 56-63.

47. Kilbreath L, Refshauge K, Beith J, Ward L, Lee M, Simpson JM, et al. Upper limb progressive resistance training and stretching exercises following surgery for early breast cancer: a randomized controlled trial. Breast Cancer Research Treatment. 2012;133: 667-676.

48. Leites G, Knorst M, Lima C, Zerwes F, Frison V. Fisioterapia em oncologia mamária : qualidade de vida e evolução clínico funcional. Revista Ciência e Saúde. 2010 ; 3 :14-21.

49. Singh C, Vera M, Campbell KL. The effect of prospective monitoring and early physiotherapy intervention on arm morbidity following surgery for breast cancer: a pilot study. Physiotherapy Canada. 2013; 65: 183-191.

50. Travier N, Velthuis M, Bisschop C, Buijs B, Mominkhaf E, Backx F, et al. Effects of an 18-week exercise programme started early during breast cancer treatment: a randomized controlled trial. BMC Medicine. 2015. doi: 10.1186/s12916-015-0362-z.

51. Gautam A, Maiya A, Vidyasagar M. Effect of home-based exercise program on lymphedema and quality of life in female postmastectomy patients : pre-post intervention study. Journal of Rehabilitation Research Development. 2011;48 : 1261-1268.

52. Poorkiani M, Abbaszadeh A, Hazrati M, Jafari P, Sadeghi M, Mohammadianpanah M. The effect of rehabilitation on quality of life in female breast cancer survivors in Iran. Indian Journal of Medical and Paediatric Oncology. 2010; 31: 105-109.

53. Moreira E, Manaia C. Qualidade de vida das pacientes mastectomizadas atendidas pelo serviço de fisioterapia do hospital universitário da universidade estadual de londrina. Ciências Biológicas e da Saúde. 2005; 26: 21 - 35. 